\title{
FORMATION OF BURIED OXIDE IN MEV OXYGEN IMPLANTED SILICON
}

\author{
C.W.NIEH, F. XIONG, C. C. AHN, Z. ZHOU*, D. N. JAMIESON, \\ T. VREELAND JR., B. FULTZ, and T. A. TOMBRELLO. \\ Materials Research Group \\ California Institute of Technology, Pasadena, CA 91125 \\ * Present address: Department of Nuclear Science, Fudan University, Shanghai, China.
}

\begin{abstract}
We have studied the formation of buried oxide in $\mathrm{MeV}$ oxygen implanted Si. A continuous oxide layer is formed in the samples implanted with $2 \times 10^{18} / \mathrm{cm}^{2}$ oxygen and annealed at $1300^{\circ} \mathrm{C}$. The microstructures are studied by cross-sectional transmission electron microscopy and high resolution electron microscopy. Chemical information was obtained by electron energy loss spectroscopy. The effects of implantation temperature are studied. Implantation at a low substrate temperature leads to a well-defined buried $\mathrm{SiO}_{2}$ layer, inhibits the formation of oxide precipitates in the silicon, and reduces silicon inclusions in the $\mathrm{SiO}_{2}$.
\end{abstract}

\section{INTRODUCTION}

Considerable effort has been made in fabricating Si-on-insulator structures. High dosage oxygen implantation is one of the most promising techniques. It has been demonstrated that with $200 \mathrm{keV}$ oxygen implantation to doses higher than $1.4 \times 10^{18} / \mathrm{cm}^{2}$, a stoichiometric $\mathrm{SiO}_{2}$ layer can be formed[1]. Buried oxides formed in subcritical dose oxygen implanted silicon have been reported $[2,3]$. Usually a high temperature $\left(1300^{\circ} \mathrm{C}\right)$ post implantation anneal is required for oxygen redistribution[4]. An alternative way of providing mobility for oxygen atoms is to implant at a high substrate temperature $\left(500^{\circ}\right.$ C). Formation of a continuous oxide layer by high temperature implantation has been reported $[5,6]$ and the microstructure of buried $\mathrm{SiO}_{2}$ has been extensively studied[7,8]. Most of the previous studies have concentrated on $\mathrm{keV}$ oxygen implantation although $1 \mathrm{MeV}$ implantation has been used[3]. High energy implantation has the advantage of retaining a high quality silicon surface layer since the implanted ions create only electronic damage near the surface, and the damage can be easily recovered by thermal annealing. The oxygen concentration in the surface region is much lower since most of the oxygen is deposited several microns away from the surface.

In this paper we first report on the microstructure of silicon implanted with $\mathrm{MeV}$ oxygen ions at various temperatures. We then show how these microstructures, especially the buried oxide layer, is changed after a high temperature annealing treatment. The microstructure of the samples was studied by cross-sectional transmission electron microscopy (XTEM). High resolution electron microscopy (HREM) was performed to study the structure of $\mathrm{Si} / \mathrm{SiO}_{2}$ interfaces and crystal defects. Electron energy loss spectroscopy (EELS) was used to study the bonding state of oxygen and silicon as well as to measure the oxygen concentration profiles.

\section{EXPERIMENTAL}


$\mathrm{N}$-type (100) silicon wafers were implanted with 2 and $5 \mathrm{MeV} \mathrm{O}^{+2}$ at doses of $1 \times 10^{15}$ to $2 \times 10^{18} / \mathrm{cm}^{2}$. The implantation was carried out on an EN-Tandem accelerator at a current density of $3-8 \mu \mathrm{A} / \mathrm{cm}^{2}$. The substrate temperatures during the implantation were $-196^{\circ} \mathrm{C}$, room temperature and $500^{\circ} \mathrm{C}$ as monitored by a thermocouple on the backside of the substrates. Due to ion beam heating the surface temperatures might be $200^{\circ} \mathrm{C}$ higher than the thermocouple reading. For the annealing experiments, the samples were sealed in quartz tubes. Before sealing the tubes were purged with He gas and evacuated. The oxygen partial pressure is estimated to be less than $10^{-6}$ Torr. The annealing temperatures were measured by an optical pyrometer with an accuracy of $\pm 10^{\circ} \mathrm{C}$.

The conventional TEM work and HREM work employed a Philips EM 430 microscope operating at $300 \mathrm{kV}$. The EELS was performed with a Gatan 607 Electron Energy Loss Spectrometer mounted on the same microscope operating at $200 \mathrm{kV}$.

\section{RESULTS AND DISCUSSION}

For the $5 \mathrm{MeV}$ oxygen implanted samples, the area of heaviest damage is about $3 \mu \mathrm{m}$ below the surface. For low dose (less than $10^{15} / \mathrm{cm}^{2}$ ) implantation, point defect clusters were formed near the damage peak. For the samples implanted with a dose higher than $1 \times 10^{16} / \mathrm{cm}^{2}$, an amorphous Si layer was formed at about $4 \mu \mathrm{m}$ from the surface. The amorphous layer thickness increased as the ion dose increased. However, an ion dose two orders of magnitude higher than $1 \times 10^{16} / \mathrm{cm}^{2}$ only doubled the amorphous layer thickness. Fig.1 shows the as-implanted structure of the sample implanted at room temperature with $1.4 \times 10^{18} \mathrm{O}^{+2} / \mathrm{cm}^{2}$. Heavily damaged crystalline zones were observed on both sides of the amorphous layer due to straggling of oxygen ions. The zones were slightly thicker than those in specimens implanted with a lower dose. No lattice damage was observed in the surface silicon layer. These results indicate that one can increase the amount of oxygen (and thus the thickness of oxide) without sacrificing the crystallinity of the surface silicon by use of $5 \mathrm{MeV} \mathrm{O}^{+2}$ implantation. High resolution imaging shows there are point defect clusters on (111) planes in samples implanted at room temperature. (see Fig.1b)but not in the samples implanted at low temperature.
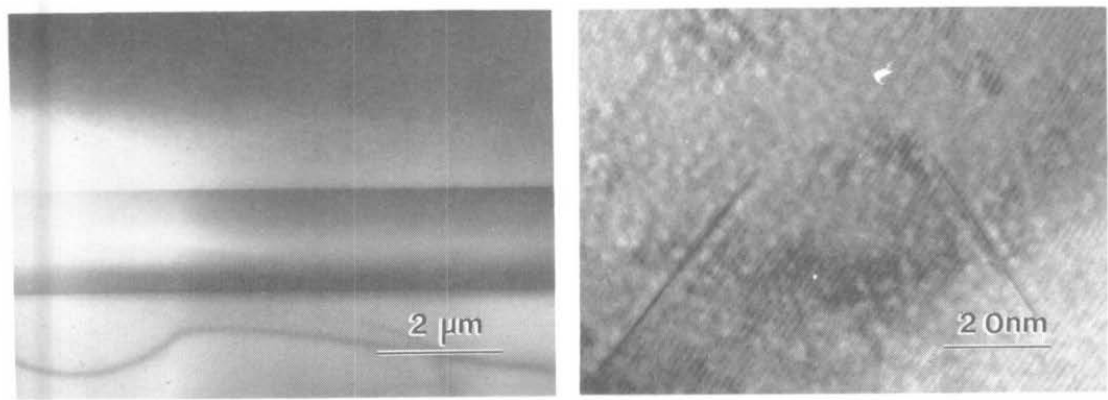

Fig.1 (a)XTEM micrograph of sample as implanted with $1.4 \times 10^{18} / \mathrm{cm}^{2}$ oxygen at room temperature, (b)HREM micrograph of the same sample as in (a) showing the planar defects. 
The maximum oxygen concentration found by EELS was located at about $4 \mu \mathrm{m}$ from the surface, in good correspondence with the microstructure observation of the amorphous layer. Fig.2 (a) shows EELS spetra from areas at two different depths from the outer interface of the sample as implanted at low temperature. The lower trace shows that little oxygen is present immediately adjacent to the outer interface. The upper spectrum is taken from an area $4 \mu \mathrm{m}$ from the surface and reveals an oxygen $\mathrm{K}$ peak with a near edge structure identical to that of $\mathrm{SiO}_{2}$. The near edge structure of this oxygen $\mathrm{K}$ transition gives a good indication of the local environment of oxygen[9] which is different from that of oxygen gas[10].
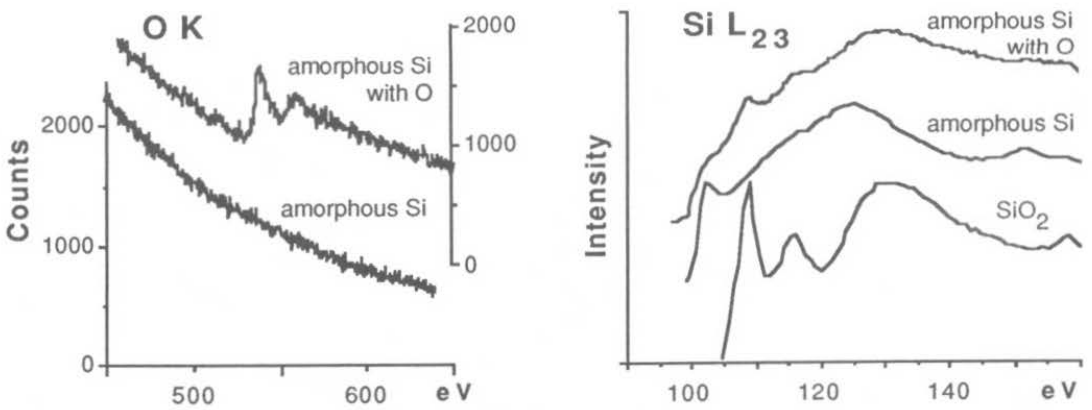

Fig.2 (a)EELS spectrum showing the oxygen $\mathrm{K}$ edge from the amorphous region of the specimen as implanted at low temperature, (b) EELS spectra showing the L edge from $\mathrm{SiO}_{2}$ and from the same amorphous region as in (a).

Nevertheless, even the center of this amorphous region does not consist entirely of amorphous $\mathrm{SiO}_{2}$. Examination of the $\mathrm{Si} \mathrm{L}_{23}$ edge in Fig.2(b) shows that the $\mathrm{L}_{23}$ structure seen in the upper spectrum is not identical to that of $\mathrm{SiL}_{23}$ from a purely amorphous $\mathrm{SiO}_{2}$. Rather, it appears to consist of a sum of contributions from both $\mathrm{SiO}_{2}$ as in the lower spectrum, and from amorphous $\mathrm{Si}$ as in the middle spectrum. The amorphous region immediately adjacent to the inner interface appears to consist entirely of amorphous silicon as in the region by the outer interface.

For the sample implanted to the critical dose $\left(1.4 \times 10^{18} / \mathrm{cm}^{2}\right)$ and annealed at $1050^{\circ}$ $\mathrm{C}$ for $1 \mathrm{~h}$, the amorphous silicon recrystallized by both solid phase epitaxial regrowth and by homogeneous nucleation (see Fig.3). A high density of microtwins was formed in the epitaxial regions. The microtwins are typical defects formed during the epitaxial growth of amorphous silicon that contains a high concentration of oxygen. Homogeneous nucleation of polycrystals was observed between the two epitaxial regions with grain sizes of $200 \AA$ near the original oxygen peak position and $400 \AA$ near the epitaxial regions (see Fig.3). The difference in oxygen concentration might cause this grain size difference. Oxide precipitates might act as nucleation sites for poly-silicon and can also inhibit the grain growth. The thicknesses of the epitaxial regions at the outer and inner interfaces of the buried layer are $200 \mathrm{~nm}$ and $50 \mathrm{~nm}$, respectively. This difference in epitaxial layer thickness also arises from the difference in oxygen concentration near the two interfaces since the growth rate is strongly dependent on oxygen concentration[11]. Oxide precipitates were formed near the original crystalline damaged zone. Near the outer interface a finer 
dispersion of oxide precipitates was found. After annealing the oxygen concentration profile was largely unchanged.

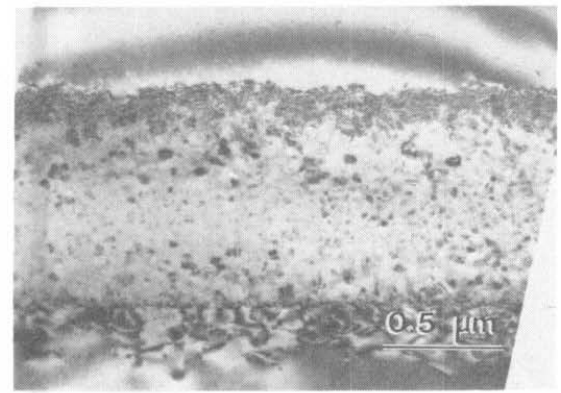

Fig.3 XTEM micrograph of the sample implanted at room temperature with a doseage of $1.4 \times 10^{18} / \mathrm{cm}^{2}$ after annealing at $1050^{\circ} \mathrm{C}$.

For the samples implanted with $2 \times 10^{18} / \mathrm{cm}^{2}$ oxygen and annealed at $1300^{\circ} \mathrm{C}$ for 1 $\mathrm{h}$, the microstructure strongly depends on the implantation temperature. For the sample implanted at room temperature (Fig.4a), the interfaces between the buried oxide and silicon are not flat and have a roughness of about $50 \mathrm{~nm}$. There are two bands of silicon inclusions inside the $\mathrm{SiO}_{2}$ layer. The inclusions are between 10 to $60 \mathrm{~nm}$ in size and are basically in the same orientation as the substrate which suggests that the inclusions are the original silicon substrate that was left behind as the oxide/silicon interface advanced into the silicon region. The position of the silicon inclusion bands corresponds to the large grain poly-silicon regions observed in the $1050^{\circ} \mathrm{C}$ annealed sample. There is also a high density of oxide precipitates in the silicon regions. The oxide precipitates are distributed within $1 \mu \mathrm{m}$ from the $\mathrm{Si} / \mathrm{SiO}_{2}$ interfaces. A high density of dislocations was observed in these layers, the dislocations appeared to be pinned by precipitates. The size of oxide precipitates near the outer and inner interfaces were $200 \mathrm{~nm}$ and $100 \mathrm{~nm}$, respectively. Both the oxide precipitates and silicon inclusions are in the shape of a truncated octahedron bounded by (111) and (100) planes. Similar precipitate shape was reported in $200 \mathrm{keV}$ oxygen implanted silicon but with a smaller size[2]. This shape is the result of the fact that the (111) planes have a higher oxidation rate. Precipitates and inclusions tend to develop into an octahedral shape which expose the most (111) planes, however, formation of (100) planes at octahedron tips reduces the curvature at the tip and further reduces the surface energy.

For the sample implanted at low temperature, a continuous oxide layer was formed after the $1300^{\circ} \mathrm{C}$ anneal (Fig.4b). A band of silicon inclusions is seen inside the oxide layer about $50 \mathrm{~nm}$ from the inner interface. The silicon inclusions are smaller than observed in Fig.4(a), but their density is higher. The $\mathrm{Si} / \mathrm{SiO}_{2}$ interfaces are flat and no oxide precipitates were observed in the silicon regions. Two bands of epitaxial silicon with a high density of microtwins were formed. A polysilicon layer is seen between the $\mathrm{SiO}_{2}$ and outer epitaxy region. The thickness of the $\mathrm{SiO}_{2}$ layer is $900 \mathrm{~nm}$. This is the maximum thickness that we can expect with this oxygen dose because it accounts for all the implanted oxygen atoms. Including all $\mathrm{SiO}_{2}$ precipitates and the uniform $\mathrm{SiO}_{2}$ layer, the total volume of $\mathrm{SiO}_{2}$ in Figs.4 (a) and (b) is nearly equal. Threading dislocations with a density of $10^{7} / \mathrm{cm}^{2}$ were observed in the sample implanted at room temperature, whereas the threading dislocation density in the sample implanted at low temperature is less than $10^{6} / \mathrm{cm}^{2}$. HREM shows 
that all the $\mathrm{SiO}_{2}$ interfaces in Fig4. (a) and (b) are atomically sharp.
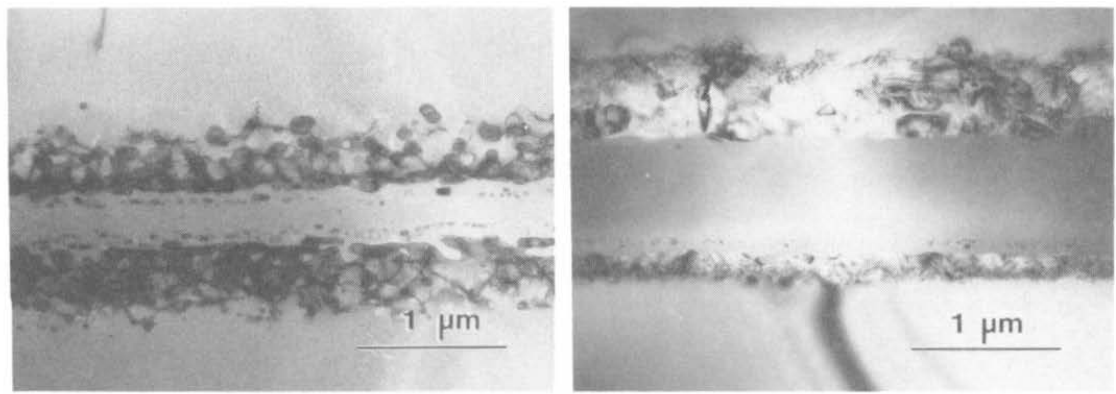

Fig.4 XTEM micrographs of samples implanted with $2 \times 10^{18} / \mathrm{cm}^{2}$ oxygen at (a)room temperature, and (b)low temperature, after annealing at $1300^{\circ} \mathrm{C}$.

For the high temperature implantation studies, $2 \mathrm{MeV} \mathrm{O}^{+2}$ was used with a dose of $1.4 \times 10^{18} / \mathrm{cm}^{2}$. The substrate was kept at $500^{\circ} \mathrm{C}$ during implantation. The as-implanted structure is shown in Fig.5 (a). A band of alternating rows of two kinds of plates was formed. HREM reveals that one kind of plate is amorphous and the other kind is a network of silicon single crystals embedded in an amorphous material, see Fig.5 (b). Between this band and the silicon are highly defective crystalline zones. A high density of defects with dislocations, stacking faults and oxide precipitates was formed in a $1 \mu \mathrm{m}$ band at a depth $1 \mu \mathrm{m}$ from the surface.
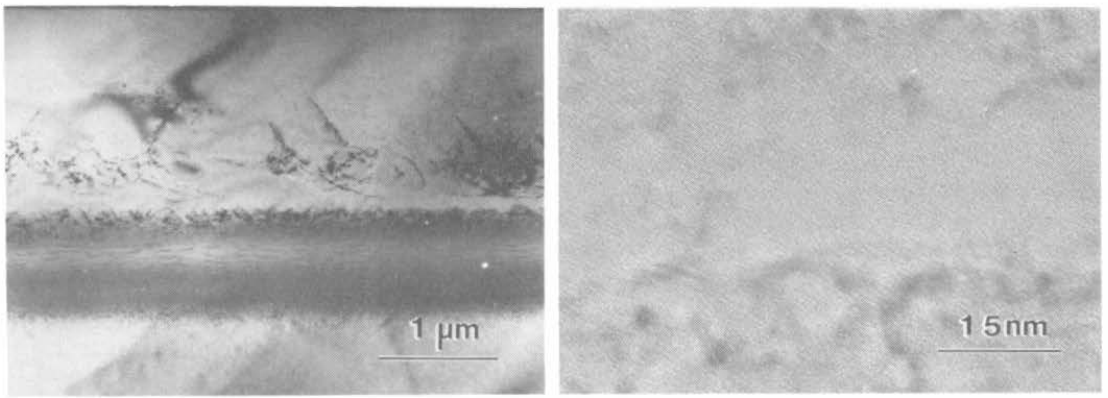

Fig.5 (a)XTEM micrograph of specimen implanted at $500^{\circ} \mathrm{C}$ with $2 \mathrm{MeV}, 1.4 \times 10^{18} / \mathrm{cm}^{2}$ oxygen, (b) HREM micrograph of same specimen showing the plate structure.

During implantation and annealing, the oxygen atoms tend to migrate to the nearest stable oxide precipitate. There is a critical radius for oxide precipitates, below which the oxide is not stable and tends to dissolve. This critical radius increases with temperature. From Fig.2 and 4(a), the smallest precipitate sizes observed at $1050^{\circ} \mathrm{C}$ and $1300^{\circ} \mathrm{C}$ are $5 \mathrm{~nm}$ and $50 \mathrm{~nm}$, respectively. To form a uniform buried $\mathrm{SiO}_{2}$ layer with a sharp $\mathrm{Si} / \mathrm{SiO}_{2}$ interface, it is important to avoid the formation of any $\mathrm{SiO}_{2}$ precipitates which exceed 
the critical radius. Implantation at low temperature might inhibit the early nucleation of oxide and thus eliminate the formation of oxide precipitates in the silicon regions.

\section{SUMMARY and CONCLUSIONS}

Silicon on insulator structure was formed by $5 \mathrm{MeV}$ oxygen ions implantated at $2 \times 10^{18} / \mathrm{cm}^{2}$ after a $1300^{\circ} \mathrm{C}$ anneal. The structure contains a $3 \mu \mathrm{m}$ surface of high quality single crystal silicon and a $900 \mathrm{~nm}$ buried $\mathrm{SiO}_{2}$ layer. The detailed structures for samples implanted at different substrate temperatures are studied. Implantation at low temperature significantly improves the buried oxide structure. Low temperature implantation eliminates the oxide precipitates inside the crystalline silicon and reduces the silicon inclusions inside the $\mathrm{SiO}_{2}$ buried layer.

\section{ACKNOWLEDGEMENT}

This work was supported in part by the NSF grant [DMR-8421119].

\section{REFERENCES}

1. G. K. Celler, Solid State Technology/March, 93 (1987)

2. J. Stoemenos, J. Margail, C. Jausscud, M. Dupuy, and M. Bruel, Appl. Phys. Lett. 48, $1470(1986)$

3. A. E. White, K. T. Short, J. L. Batstone, D. C. Jacobson, J. M. Poate, and K. W. West, Appl. Phys. Lett. 50, 19 (1986)

4. G. K. Celler, P. L. F. Hemment, W. K. West, and J. M. Gibson, Appl. Phys. Lett. $48,532(1986)$

5. C. G. Tuppen, M. R. Taylor, P. L. F. Hemment, and R. D. Arrowsmith, Appl. Phys. Lett. 45,57 (1984)

6. A. E. White, K. T. Short, L. N. Pfeiffer, K. W. West, and J. L. Batstone, Mat. Res. Soc. Symp. Proc. Vol.74, 585 (1987)

7. M. K. El-ghor, S. J. Pennycook, T. P. Sjoreen, and J. Narayan, Mat. Res. Soc. Symp. Proc. Vol.74, 591, (1987)

8. J. L. Batstone, A. E. White, K. T. Short, J. M. Gibson, and D. C. Jacobson, Mat. Res. Soc. Symp. Proc. Vol.74, 597, 1987.

9. Tafto, J. and Zhu, J., Ultramicroscopy, 9, 349-354 (1982)

10. C. C. Ahn, and O. L. Krivarek, EELS Atlas, Center for Solid State Science, Arizona State University, Tempe AZ 85287 (1983)

11. E. F. Kennedy, L. Csepregi, J. M. Mayer, and T. W. Sigmon, J. Appl. Phys. 48, 4241 (1977) 